\title{
Education of Autistic Children in Developing Countries
}

\author{
Yitong Lin \\ University College London, London, UK \\ Email: yitonglin1999@outlook.com
}

How to cite this paper: Lin, Y. T. (2021). Education of Autistic Children in Developing Countries. Open Journal of Social Sciences, 9, 109-117.

https://doi.org/10.4236/jss.2021.910008

Received: September 2, 2021

Accepted: October 16, 2021

Published: October 19, 2021

Copyright $\odot 2021$ by author(s) and Scientific Research Publishing Inc. This work is licensed under the Creative Commons Attribution International License (CC BY 4.0).

http://creativecommons.org/licenses/by/4.0/

\begin{abstract}
Although a large number of studies have focused on inclusive education in developed countries, there are few research on developing countries, especially China. Therefore, this paper mainly discusses whether autistic children in China should be educated separately from ordinary students. The thesis is mainly composed of three parts. Firstly, it introduces the definition of disability, inclusive education and its background in China. Secondly, the advantages and challenges of inclusive education in China are discussed through cases. It concluded that children with autism should be educated together with ordinary students to promote educational equality and help autistic children integrate into society. However, parents' attitudes and the limitations of teachers' knowledge in mainstream schools are the great challenges facing inclusive education in China.
\end{abstract}

\section{Keywords}

Inclusive Education, Special Needs Education, ASD Children

\section{Introduction}

This essay will discuss whether children with autism spectrum disorder (ASD) should be educated separately to attain both academic and social achievements. Since there have been many investigations and studies on inclusive education in developed countries, this essay will pay attention to developing countries. Therefore, China's inclusive education for children with autism will be used as an example to reveal the advantages of inclusive education as well as its challenges. For this purpose, this essay will use inclusive education as a theoretical framework. In order to obtain a deeper comprehension of the status quo of China's inclusive education, this essay will review some case studies about inclusive education in both mainland China and Hong Kong from Yang (2010) and Peters and Forlin (2011).

In order to have a preliminary comprehension of the concept of inclusive 
education, the first section will mainly discuss the definitions of disability and special education as well as the brief historical background of inclusive education in China, which focuses on its developmental process. Secondly, the advantages of inclusive education will be discussed. Then it will investigate some Chinese case studies related to inclusive education from several aspects, including inclusive education's contribution to educational equality in China and Chinese ASD children's integration into regular classes. Meanwhile, the current challenges within inclusive education in China will also be evaluated.

Since the concept of inclusive education was proposed, some developed countries have achieved great results in this regard (Yao, 2007). However, whether the children with special needs should be admitted to mainstream schools still has aroused controversies (Savich, 2008). Therefore, this essay will explore the controversies related to the inclusive education, and argue that children with disabilities should be taught with their ordinary peers, and the inclusive education should be suitable for the students with ASD, yet, there are still some barriers needed to be broken down.

\section{Background}

There is no precise definition of disability, as its definition may vary according to different contexts over the years (Patel \& Brown, 2017). The International Classification of Functioning, Disability, and Health from the World Health Organization (2001) defined disability from body function and structure, activity and participation, as well as the environmental factors (WHO, 2001). In China, from the statement of the People with Disabilities Act of the Peoples Republic of China (Standing Committee of the National People's Congress, 2008), disabled people refer to those who have lost a specific organ in the physical structure of the human body or has abnormal function psychologically, and thus totally or partially being unable to engage a certain activity normally. For the purpose of this essay, this definition will be adopted as the working definition.

Children with ASD account for a large group of disabled people in China. ASD refers to a neurodevelopmental disorder including symptoms such as continuous defects with social interactions and communication, as well as repetitive patterns of behavior (American Psychiatric Association, 2013). According to statistics, children with autism make up $1 \%$ of the total number of children (Baird et al., 2006). Therefore, it can be estimated that the number of children with autism in mainland China is more than 2 million based on the national census in 2019 in mainland China, where the total population of children aged $0-14$ was 234.9 million (National Bureau of Statistics, 2019).

When the difficult situations for the disabled children are realized, special education has appeared accordingly. Special education refers to a kind of education that is linked with children who face special challenges and requirements (Maryanti et al., 2021). After that, inclusive education has derived from special education (Zhang, 2014) and developed in a long term under the promotion of international organizations. In 1994, the Salamanca Statement was formulated 
by UNESCO (1994), and the concept of inclusive education was born, all discriminatory educational policies are challenged as well as achieving universal education through this statement (UNESCO, 1994). The UK is one of the first countries to propose the notion of inclusive education. As early as 1978, The Warnock Report (Department for Education and Science, 1978) stated that children with disabilities should receive education in regular schools.

According to the Guidelines for Inclusion from UNESCO (2005), the definition of inclusive education is a process to identify and respond to the diverse needs of all learners by promoting involvement and participation in learning culture, as well as diminishing exclusion from education. Similarly, Moriña (2017) noted that inclusive education refers to an educational method in which every student is involved and be treated as valuable members, with the purpose of improving the learning and engagement of all students in a common educational setting. Despite some similarities in these definitions of inclusive education, the working definition of this essay will adopt the definition from Huang (2004), which not only explains inclusive education as a long-term education model requiring all students' participation, regardless of disabled or non-disabled students, but also claims that it requires both the engagement and the cooperation of parents in the educational process.

\section{Current Situation of Education in China}

Compared with developed countries, China starts to implement inclusive education relatively late. Since instituting inclusive education necessitates educational changes such as institution, curriculum, teaching, and evaluation, which may fail to be reformed without the support from specific laws and policies (Watkins, 2009). Hence the Chinese government has also implemented a series of reformed policies (Carrington et al., 2015). In the beginning, the Constitution, the first legislation to make special education mandatory in China amended in 1982, provides for education and social assistance for people with special educational needs (Deng \& Poon-McBrayer, 2012). However, it is not until China's the open-door reform policy in the 1980, that the concept of inclusion was officially introduced (Deng \& Poon-McBrayer, 2012). The theory of "study in regular class" is the inclusive education localized in China, which was first put forward in 1988 in Five-Year Work Program for Disabled Persons (State Council, 1988). In 1994, when the Trial Measures on Carrying out the Work or Disabled Children Studying in Classes and the Regulations on Education of Persons with Disabilities (State Education Commission, 1994) were introduced, the inclusive education in China was gradually legalized.

\section{Review the Advantages and Barriers of Inclusive Education through the Case Study}

\subsection{Equality of Education}

Many scholars believe that the benefits brought by inclusive education are sig- 
nificant, and a key advantage is that it makes the societal integration of impaired pupils become possible (Savich, 2008). Inclusion involves stronger social cohesiveness, a greater awareness of empathy, and a larger feeling of diversity (Savich, 2008). Therefore, inclusive education means that all pupils have equal rights and supports (Savich, 2008). In addition, it challenges the traditional model of education, and the differences between people are regarded as normal (Wang \& Yu, 2002). Thus, in this sense, children with special needs can also receive the same and equal education as ordinary children under inclusive education (Wang \& Yu, 2002).

Currently, China is paying more attention to achieve educational equality, which is a key component of inclusive education (Su et al., 2020). This means that children with ASD can be incorporated into a more diversified education to achieve educational equity and after these children make contributions to their own development at school, they would obtain a fair chance in society in the future. In Hong Kong, for example, the education department has offered adequate support to inclusive education in schools with the implementation of the Whole School Approach (WSA) (Peters \& Forlin, 2011). The WSA supports schools in terms of developing inclusive education policies, including identification, progress monitoring, evaluation, interventions, adaptation, and curriculum modification (Peters \& Forlin, 2011). In Hong Kong, the WSA can provide places to students with ASD in primary schools (Peters \& Forlin, 2011). In addition, numerous teaching and learning materials are provided by the Education Bureau for mainstream school teachers to gain a better understanding of the children with autism (Peters \& Forlin, 2011). With this educational support, autistic children in Hong Kong can receive the same education as ordinary students. Moreover, special teaching materials offered by the Education Bureau somewhat enable mainstream teachers to help autistic children keep up with the learning progress of ordinary students when necessary.

However, due to some parents' attitudes, some children with autism cannot really get equal education to some extent. Sometimes a parent's attitude towards inclusive education may become a barrier for their autistic children accessing mainstream schools. According to Su et al. (2020), Chinese parents are probably more effective influences on inclusive education than its policy intervention. Currently, there are no mandatory laws in China on whether autistic children should be included in mainstream classes, so the parental choice is crucial (Deng \& Zhu, 2016). Differing from western countries, parental choices are greatly affected by Chinese culture, where the issue of losing face is deeply settled in Chinese people's minds (Peters \& Forlin, 2011). Specifically, if inclusive education cannot promise that their autistic children can achieve the same academic performance as those ordinary students, they may turn to special education to avoid "losing face" (Peters \& Forlin, 2011). As a result, Chinese parents often do not actively seek inclusive education for their autistic children, and when making choices between mainstream education and special education, they tend to 
choose the latter as they believe that teachers there are better trained so that their children will not suffer stigma or isolation in special education schools (Peters \& Forlin, 2011; Su et al., 2020).

Moreover, as inclusive education has not been well implemented nationwide, China is still unable to fully guarantee that children with disabilities in all regions can receive equal education, especially for ethnic minorities with lower living standard and lack of financial support (Zhang, 2014). Even though China has regulations on Education of Person with Disabilities, there is no specific legislation about it like the prioritized Compulsory Education Law, thus, under such circumstances, the equal right to education for disabled children cannot be fully guaranteed (Zhang, 2014).

\subsection{Improve the Ability to Adapt to Society}

In addition to educational equity, promoting autistic children's ability to communicate with others and to adapt to society is another advantage brought by inclusive education. The symptoms of autism, usually appearing in early childhood and persisting through growth are characterized by an inability to engage in normal social interactions, difficult verbal and non-verbal communication, and repetition of the same behaviors (Roleska et al., 2018). If they are educated in an isolated environment, their interpersonal skills will not improve at all. Research has shown that inclusive classrooms can help students with disabilities build self-esteem and promote their self-concept, as well as build social skills such as communication skills and social adjustment in interactions (Wolfberg \& Schuler, 1999). Further, children with disabilities can even gain friendship with ordinary children by interacting with their peers in an inclusive educational environment (Fryxell \& Kennedy, 1995). Yang (2010) used to conduct questionnaires, interviews, and field observation in 47 primary schools with inclusive education in Beijing and Shanghai. The results show that students with disabilities have made significant progress in several aspects of inclusive education, including social skills, academic performance, and self-confidence (Yang, 2010). Therefore, under the inclusive education, autistic children can learn as ordinary students, and by interacting with peers, their social skills, self-confidence, and academic level would be well developed so that they could be able to be integrated into society in the future.

However, the academic development of autistic children is challenged by the limited knowledge of teachers in mainstream schools. Some scholars indicate that common teaching techniques and strategies in mainstream schools often fail to be used with autistic children (Frederickson \& Cline, 2009). Moreover, some researchers argue that without a certain understanding of ASD, including its characteristics, diagnosis, causes, and definitions, the curriculum and teaching strategies cannot be applied effectively to teach ASD children social skills and communication (Scheuermann et al., 2003). Due to the absence of training and relevant resources, regular schools' teachers generally lack the skills, knowledge 
and experience to teach disabled students (McBrayer, 2016). This challenge is also heavily reflected in local research in China. For example, a recent study from $\mathrm{Lu}$ et al. (2020) surveyed 410 teachers from 12 mainstream elementary schools in Guangdong Province, China, asking participants to take the questionnaire with questions related to the autism stigma and knowledge (ASK-Q). The results showed that the accuracy of their answers was only $53.9 \%$ on average and the lowest rate was only $10 \%$, which reflects that most teachers do not understand the causes of autism (Lu et al., 2020). Apart from mainland China, surveys in Hong Kong found a similar pattern. Some teachers admit that lacking both professional knowledge and experience results in having no confidence in educating the children with special education needs (Peters \& Forlin, 2011). It can be seen that even though children with autism may gain both academic skill and communication skills from inclusive education, teachers lacking understanding of ASD and professional teaching skills may fail to teach the students with autism in an effective way.

\subsection{Suggestions for Addressing These Barriers}

At first, the government should enact special education laws, and to make them more workable, and to strengthen the enforcement of special education laws, the use of ambiguous words such as "should" should be eliminated (Zhang, 2014). Advocate national policy to establish rules that schools do not exclude any autistic children, so that children with autism can be legally guaranteed to attend classes. The state should devote itself to raising funds for special education and give preference to schools that provide compulsory education for special children (Zhang, 2014).

More importantly, some traditional social values need to be changed. It is suggested that the government make a propaganda video for autistic children, so that the public can treat autistic children with an inclusive attitude and an accepting attitude. Schools can use lectures and WeChat public accounts to publicize integrated education to parents, so that parents of normal children can care about autistic children. Schools should incorporate the concept of equality and respect for individual differences into the curriculum. For example, the education on respect for special students has been added into Hong Kong's citizenship curriculum, which promotes the development of inclusive education in Hong Kong (Zhang, 2014). By this, parents with autistic children would not feel that they may lose face if their children behave differently from other students, and not worry that their children would be isolated or even insulted in a mainstream class.

In addition, the department of education could provide teachers with more support, such as promoting cooperation and communication among teachers from mainstream schools, experts from special education schools and some psychologists, so as to enable these teachers to gain more professional knowledge and increase their confidence in teaching ( $\mathrm{Lu}$ et al., 2020). Moreover, as for 
schools, they could reform some policies for autistic children to adapt to the normal classroom curriculum more quickly. For example, schools could initiate some learning programs that are suitable for autistic children as long as they do not affect the progress of ordinary students.

\section{Conclusion}

In conclusion, this essay aims to discuss whether autistic children should be educated separately to avoid underachievement. The selection of China as the main country for discussion reflects the progress of inclusive education in developing countries. This essay has argued that despite some challenges, inclusive education can help children with autism in China to achieve better academic performance and social integration. At present, China has made some achievements in the implementation of inclusive education, but due to the imperfect legislation, deep-rooted traditional values and the allocation of teacher resources, inclusive education has not been able to give full play to its greatest advantages. Education is the right of every child so that autistic children should also be treated equally and receive diversified education. The education department in Hong Kong has made a good attempt to support the inclusive education of these autistic children. Although schools and other educational authorities make efforts to support autistic children for their entrance into mainstream classes, the traditional views of some Chinese parents, who are reluctant to allow their autistic children to study in the regular classroom for fear of losing face, may become a barrier. In addition, due to the lack of financial support in the remote areas of China, many autistic children cannot receive inclusive education. Therefore, it is recommended to enforce the Disability Education Law to ensure that every autistic child has a chance to access education. Even though inclusive education can promote both social skills and communication skills of children with ASD, teachers' inadequate knowledge of autism and teaching experience may restrict the development of autistic children in mainstream classes. Accordingly, it is recommended that education departments should train ordinary teachers by instilling professional knowledge and skills, and schools should create learning content suitable for students with ASD. In general, instead of being taught separately from their normal peers, children with autism should be educated in mainstream classes on the basis of the barriers mentioned being tackled. Therefore, China still has a long way to go to fully embrace inclusive education.

\section{Conflicts of Interest}

The author declares no conflicts of interest regarding the publication of this paper.

\section{References}

American Psychiatric Association (2013). Diagnostic and Statistical Manual of Mental 
Disorders $\left(D S M-5^{\circledR}\right)$. American Psychiatric Pub. https://doi.org/10.1176/appi.books.9780890425596

Baird, G., Simonoff, E., Pickles, A., Chandler, S., Loucas, T., Meldrum, D., \& Charman, T. (2006). Prevalence of Disorders of the Autism Spectrum in a Population Cohort of Children in South Thames: The Special Needs and Autism Project (SNAP). The Lancet, 368, 210-215. https://doi.org/10.1016/S0140-6736(06)69041-7

Carrington, S., Saggers, B., Adie, L., Zhu, N., Gu, D., Hu, X., Wang, Y., Deng, M., \& Mu, G. M. (2015). International Representations of Inclusive Education: How Is Inclusive Practice Reflected in the Professional Teaching Standards of China and Australia? International Journal of Disability, Development and Education, 62, 556-570. https://doi.org/10.1080/1034912X.2015.1077933

Deng, M., \& Poon-McBrayer, K. F. (2012). Reforms and Challenges in the Era of Inclusive Education: The Case of China. British Journal of Special Education, 39, 117-122. https://doi.org/10.1111/j.1467-8578.2012.00551.x

Deng, M., \& Zhu, X. (2016). Special Education Reform towards Inclusive Education: Blurring or Expanding Boundaries of Special and Regular Education in China. Journal of Research in Special Educational Needs, 16, 994-998.

https://doi.org/10.1111/1471-3802.12244

Department for Education and Science (1978). The Warnock Report. London.

Frederickson, N., \& Cline, A. (2009). Special Educational Needs Inclusion and Diversity. McGraw-Hill Education.

Fryxell, D., \& Kennedy, C. H. (1995). Placement along the Continuum of Services and Its Impact on Students' Social Relationships. Journal of the Association for Persons with Severe Handicaps, 20, 259-269. https://doi.org/10.1177/154079699602000403

Huang, Z. (2004). Inclusive Education: Focuses on the Learning and Participation of All Students. Shanghai Education Press.

Lu, M., Zou, Y., Chen, X., Chen, J., He, W., \& Pang, F. (2020). Knowledge, Attitude and Professional Self-Efficacy of Chinese Mainstream Primary School Teachers Regarding Children with Autism Spectrum Disorder. Research in Autism Spectrum Disorders, 72, 1-12. https://doi.org/10.1016/j.rasd.2020.101513

Maryanti, R., Nandiyanto, A. B. D., Hufad, A., \& Sunardi, S. (2021). Science Education for Students with Special Needs in Indonesia: From Definition, Systematic Review, Education System, to Curriculum. Indonesian Journal of Community and Special Needs Education, 1, 1-8.

McBrayer, K. F. P. (2016). Resource Room Model for Inclusive Education in China: Practitioners' Conceptualisation and Contextualisation. International Journal of Learning and Change, 8, 317-331. https://doi.org/10.1504/IJLC.2016.081616

Moriña, A. (2017). Inclusive Education in Higher Education: Challenges and Opportunities. European Journal of Special Needs Education, 32, 3-17. https://doi.org/10.1080/08856257.2016.1254964

National Bureau of Statistics (2019). The Age Structure and Dependency Ratio of the Population in 2019. https://data.stats.gov.cn/easyquery.htm? $\mathrm{cn}=\mathrm{C} 01 \& \mathrm{zb}=\mathrm{A} 0301 \& \mathrm{sj}=2020$

Patel, D. R., \& Brown, K. A. (2017). An Overview of the Conceptual Framework and Definitions of Disability. International Journal of Child Health and Human Development, 10, 247-252.

Peters, B., \& Forlin, C. (2011). Chinese Children with ASD in Hong Kong (SAR): Development of Inclusive Practice. Journal of Research in Special Educational Needs, 11, 
87-98. https://doi.org/10.1111/j.1471-3802.2010.01179.x

Roleska, M., Roman-Urrestarazu, A., Griffiths, S., Ruigrok, A. N. V., Holt, R., van Kessel, R., McColl, K., Sherlaw, W., Brayne, C., \& Czabanowska, K. (2018). Autism and the Right to Education in the EU: Policy Mapping and Scoping Review of the United Kingdom, France, Poland and Spain. PLoS ONE, 13, e0202336. https://doi.org/10.1371/journal.pone.0202336

Savich, C. (2008). Inclusion: The Pros and Cons-A Critical Review.

Scheuermann, B., Webber, J., Boutot, E. A., \& Goodwin, M. (2003). Problems with Personnel Preparation in Autism Spectrum Disorders. Focus on Autism and Other Developmental Disabilities, 18, 197-206. https://doi.org/10.1177/10883576030180030801

Standing Committee of the National People's Congress (2008). People with Disabilities Act of the Peoples Republic of China (Chapter 1, Article 2).

State Council (1988). Work Program for Disabled Persons during the Period of the Eighth Five-Year National Development Plan (1991-1995). Hua Xia.

State Education Commission (1994). The Trial Measures on Carrying out the Work of Disabled Children Studying in Classes and Regulations on Education of Reasons with Disabilities. http://www.bjchy.gov.cn/affair/zfyj/law/16129.htm

Su, X., Guo, J., \& Wang, X. (2020). Different Stakeholders' Perspectives on Inclusive Education in China: Parents of Children with ASD, Parents of Typically Developing Children, and Classroom Teachers. International Journal of Inclusive Education, 24, 948-963. https://doi.org/10.1080/13603116.2018.1502367

UNESCO (1994). The Salamanca Statement and Framework for Action on Special Needs Education. Unesco.

UNESCO (2005). Guidelines for Inclusion: Ensuring Access Education for All. http://www.ibe.unesco.org/sites/default/files/Guidelines for_Inclusion UNESCO 200 6.pdf

Wang, P., \& Yu, X. (2002). Educational Equity Is the Core Connotation of Inclusive Education. Chinese Journal of Special Education, 3, 3-6.

Watkins, M. (2009). "Inclusive Education: The Way of the Future"-A Rebuttal. Prospects, 39, 215-225. https://doi.org/10.1007/s11125-009-9123-0

Wolfberg, P. J., \& Schuler, A. L. (1999). Fostering Peer Interaction, Imaginative Play and Spontaneous Language in Children with Autism. Child Language Teaching and Therapy, 15, 41-52. https://doi.org/10.1177/026565909901500105

World Health Organization (2001). International Classification of Functioning, Disability and Health.

https://www.who.int/standards/classifications/international-classification-of-functioni ng-disability-and-health

Yang, X. (2010). Study on the Development of Disabled Students on Learning in Regular Class. Chinese Journal of Special Education, No. 7, 3-10.

Yao, W. (2007). Research Significance of Inclusive Education. Journal of North China Institute of Water Conservancy and Hydropower (Social Science Edition), 5.

Zhang, J. (2014). The Development of Special Education in China under the Trend of Inclusive Education-Taking Hong Kong's Inclusive Education as an Example. SME Management and Technology (Mid-10 Issue), No. 7, 298-300. 